\title{
Ruthenium-Catalyzed Mild C-H Oxyfunctionalization of Cyclic Steroidal Ethers.
}

\author{
Jong Seok Lee, ${ }^{\S}$ Hui Cao and Philip L. Fuchs* \\ Department of Chemistry, Purdue University, West Lafayette, Indiana 47907 \\ pfuchs@purdue.edu
}

\section{Supporting Information}

\section{Table of contents}

$\begin{array}{ll}\text { General Experimental } & \text { S2 }\end{array}$

$\begin{array}{ll}\text { Phosphate Buffer Preparation } & \text { S2 }\end{array}$

$\begin{array}{ll}\text { Characterization Checklist } & \text { S3 }\end{array}$

Analytical Data for Newly Synthesized Compounds $\quad$ S5

$\begin{array}{ll}{ }^{1} \mathrm{H} \text { NMR Data for Previously Synthesized Compounds } & \text { S7 }\end{array}$

${ }^{1} \mathrm{H}$ and ${ }^{13} \mathrm{C}$ NMR Spectra of Newly Synthesized Compounds $\quad$ S10

${ }^{1}$ H NMR Spectra of Previously Synthesized Compounds $\quad$ S18 


\section{General Experimental}

All reactions were carried out at room temperature under atmospheric pressure. Thin layer chromatography (TLC) was used to monitor the progress of reactions by co-spotting with the starting materials. $p$-Anisaldehyde $\left(1350 \mathrm{~mL}\right.$ absolute ethanol, $50 \mathrm{~mL}$ concentrated $\mathrm{H}_{2} \mathrm{SO}_{4}$, $37 \mathrm{~mL} p$-anisaldehyde) was utilized as a common TLC visualizing solution. Possible existence of peroxide in the reaction mixtures was checked by potassium iodide strip.

Flash chromatographic purifications were performed using silica gel (230-400 mesh). ${ }^{1} \mathrm{H}$ NMR and ${ }^{13} \mathrm{C}$ NMR data were recorded in chloroform- $\mathrm{d}_{1}\left(\mathrm{CDCl}_{3}\right)$ or pyridine- $\mathrm{d}_{5}\left(\mathrm{C}_{5} \mathrm{D}_{5} \mathrm{~N}\right)$ and are described in parts per million (ppm) from the residual chloroform (7.24 ppm and $77.0 \mathrm{ppm})$ or pyridine (8.74 ppm and $150.35 \mathrm{ppm}$ ) standard, respectively.

Melting points were obtained on a capillary melting point apparatus or automated melting point system and are uncorrected.

\section{Phosphate Buffer Preparation}

To make $\mathrm{pH}=7.5$ phosphate buffer with $0.8 \mathrm{M}$ buffer capacity, $46.7 \mathrm{~g}$ of sodium phosphate monobasic monohydrate $\left(\mathrm{NaH}_{2} \mathrm{PO}_{4} \cdot \mathrm{H}_{2} \mathrm{O}\right)$ and $123.7 \mathrm{~g}$ of sodium phosphate dibasic heptahydrate $\left(\mathrm{Na}_{2} \mathrm{HPO}_{4} .7 \mathrm{H}_{2} \mathrm{O}\right)$ were dissolved in $1 \mathrm{~L}$ of deionized water. 


\section{Characterization Checklist}

\begin{tabular}{|c|c|c|c|c|c|}
\hline Compound & ${ }^{1} \mathrm{H}$ NMR & ${ }^{13} \mathrm{C}$ NMR & HRMS & LRMS & Reference $^{\mathrm{a}}$ \\
\hline & - & - & - & - & $\begin{array}{l}\text { Lee, J. S.; Fuchs, P. L. Org. } \\
\text { Lett. 2003, 5, } 2247 .\end{array}$ \\
\hline & - & - & - & - & $\begin{array}{l}\text { Lee, J. S.; Fuchs, P. L. Org. } \\
\text { Lett. 2003, 5, } 2247 .\end{array}$ \\
\hline & $\begin{array}{c}\mathrm{O} \\
\left(\mathrm{C}_{5} \mathrm{D}_{5} \mathrm{~N}\right)\end{array}$ & $\begin{array}{c}\mathrm{O} \\
\left(\mathrm{C}_{5} \mathrm{D}_{5} \mathrm{~N}\right)\end{array}$ & $\mathrm{O}$ & $\mathrm{O}$ & $\begin{array}{l}\text { Bovicelli, P.; Lupattelli, P.; } \\
\text { Francassi, D. Tetrahedron } \\
\text { Lett. 1994, 35, 935. }^{\text {. }}\end{array}$ \\
\hline & - & - & - & - & $\begin{array}{l}\text { Bovicelli, P.; Lupattelli, P.; } \\
\text { Francassi, D. Tetrahedron } \\
\text { Lett. 1994, 35, } 935 .\end{array}$ \\
\hline & - & - & - & - & $\begin{array}{l}\text { Lee, S.; Fuchs, P. L. Org. } \\
\text { Lett. 2004, 6, } 1437 .\end{array}$ \\
\hline & $\mathrm{O}$ & $\mathrm{O}$ & $\mathrm{O}$ & $\mathrm{O}$ & N.A. \\
\hline & - & - & - & - & $\begin{array}{l}\text { Lee, S.; Fuchs, P. L. Org. } \\
\text { Lett. 2004, 6, } 1437 .\end{array}$ \\
\hline & $\mathrm{O}$ & $\mathrm{O}$ & $\mathrm{O}$ & $\mathrm{O}$ & N.A. \\
\hline & $\mathrm{O}$ & $\mathrm{O}$ & $\mathrm{O}$ & $\mathrm{O}$ & N.A. \\
\hline
\end{tabular}




\begin{tabular}{|c|c|c|c|c|l|}
\hline Compound & ${ }^{1} \mathrm{H}$ NMR & ${ }^{13} \mathrm{C}$ NMR & HRMS & LRMS & \multicolumn{1}{|c|}{ Reference $^{\mathrm{a}}$} \\
\hline
\end{tabular}

a. For NMR spectra not shown in this supporting information, see the indicated references. $b$. NMR spectra were recorded in pyridine- $d_{5}$. 


\section{Analytical Data for Newly Synthesized Compounds}

(Compounds 9, 14, 17, 18)

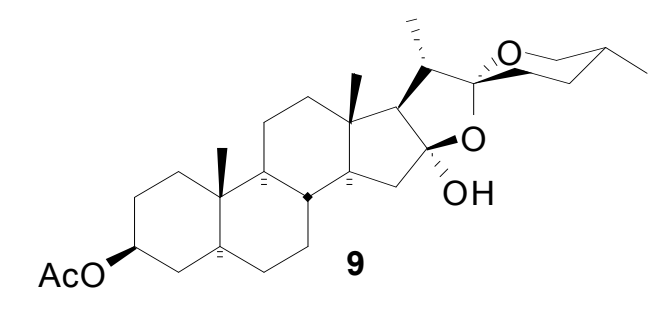

White powder, m.p. $179 \sim 180{ }^{\circ} \mathrm{C}\left(\mathrm{CH}_{2} \mathrm{Cl}_{2} / \mathrm{n}\right.$-Hexane); ${ }^{1} \mathrm{H}$ NMR $\left(300 \mathrm{MHz}, \mathrm{C}_{5} \mathrm{D}_{5} \mathrm{~N}\right) \delta 6.08$ (br s, 1H), $4.79-4.86(\mathrm{~m}, 1 \mathrm{H}), 3.86(\mathrm{t}, J=10.5 \mathrm{~Hz}, 1 \mathrm{H}), 3.59$ (d, $J=10.5 \mathrm{~Hz}, 1 \mathrm{H}), 2.23$ (d, $J=5.9$ $\mathrm{Hz}, 1 \mathrm{H}), 2.06$ (s, 3H), 1.20 (d, $J=6.4 \mathrm{~Hz}, 3 \mathrm{H}), 0.86$ (s, 3H), 0.75 (s, 3H), 0.66 (d, J=4.1 Hz, $3 \mathrm{H}) ;{ }^{13} \mathrm{C}$ NMR $\left(75 \mathrm{MHz}, \mathrm{C}_{5} \mathrm{D}_{5} \mathrm{~N}\right) \delta 170.7,116.1,110.9,74.1,71.4,68.2,56.0,54.6,45.1,43.3$, 42.7, 40.9, 40.8, 37.2, 36.2, 35.3, 34.8, 33.4, 32.8, 31.0, 29.7, 29.1, 28.2, 21.8, 17.8, 16.4, 15.7, 12.7; HRMS (ESI) $\mathrm{C}_{29} \mathrm{H}_{46} \mathrm{O}_{5} \mathrm{Na}[\mathrm{M}+\mathrm{Na}]^{+}$calcd. 497.3243, found 497.3239.

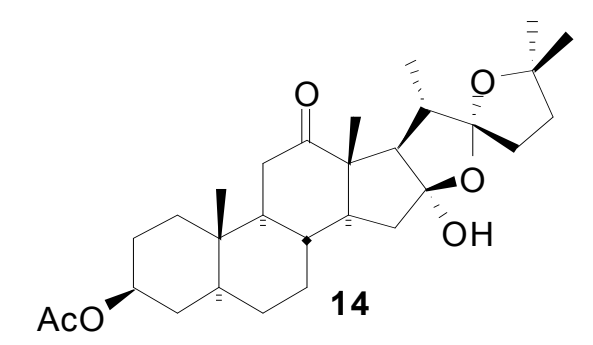

White powder, m.p. $166 \sim 167{ }^{\circ} \mathrm{C}\left(\mathrm{CH}_{2} \mathrm{Cl}_{2} / \mathrm{n}\right.$-Hexane); ${ }^{1} \mathrm{H}$ NMR $\left(300 \mathrm{MHz}, \mathrm{CDCl}_{3}\right) \delta 4.57-$ $4.65(\mathrm{~m}, 1 \mathrm{H}), 2.47$ (d, $J=7.6 \mathrm{~Hz}, 1 \mathrm{H}), 2.33(\mathrm{t}, J=13.8 \mathrm{~Hz}, 1 \mathrm{H}), 2.18(\mathrm{dd}, J=14.4,5.0 \mathrm{~Hz}, 1 \mathrm{H})$, $1.95(\mathrm{~s}, 3 \mathrm{H}), 1.34(\mathrm{~s}, 3 \mathrm{H}), 1.12(\mathrm{~s}, 3 \mathrm{H}), 1.01(\mathrm{~d}, J=6.4 \mathrm{~Hz}, 3 \mathrm{H}), 0.95(\mathrm{~s}, 3 \mathrm{H}), 0.85(\mathrm{~s}, 3 \mathrm{H}) ;{ }^{13} \mathrm{C}$ NMR $\left(75 \mathrm{MHz}, \mathrm{CDCl}_{3}\right)$ d 212.7, 170.4, 121.1, 113.3, 83.3, 73.1, 61.8, 56.0, 55.2, 54.4, 44.3, 39.5, 37.6, 37.4, 36.9, 36.0, 36.0, 35.9, 33.8, 33.7, 33.6, 31.1, 29.6, 28.1, 28.0, 27.1, 21.3, 14.8, 13.3, 11.7; $\mathrm{HRMS}$ (ESI) $\mathrm{C}_{29} \mathrm{H}_{44} \mathrm{O}_{6} \mathrm{Na}[\mathrm{M}+\mathrm{Na}]^{+}$calcd. 511.3036, found 511.3038. 


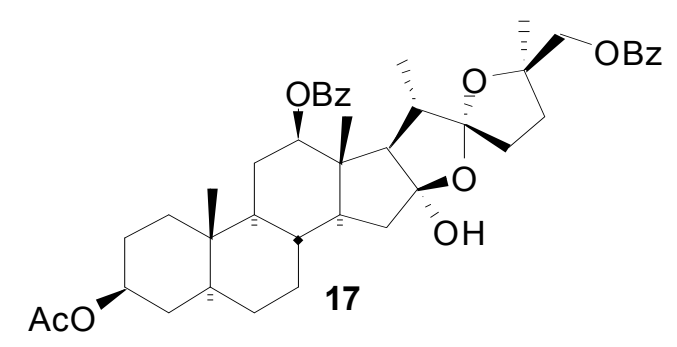

Colorless oil; ${ }^{1} \mathrm{H}$ NMR (300 MHz, $\left.\mathrm{CDCl}_{3}\right) \delta 7.94-7.98(\mathrm{~m}, 4 \mathrm{H}), 7.51-7.55$ (m, 2H), 7.37 $7.43(\mathrm{~m}, 4 \mathrm{H}), 4.94(\mathrm{dd}, J=10.8,4.1 \mathrm{~Hz}, 1 \mathrm{H}), 4.63-4.70(\mathrm{~m}, 1 \mathrm{H}), 4.08(\mathrm{dd}, J=29.9,11.1 \mathrm{~Hz}$, 2H), 2.15 (q, $J=7.0 \mathrm{~Hz}, 1 \mathrm{H}), 1.99$ (s, 3H), 1.48 (s, 3H), 0.95 (s, 3H), 0.83 (s, 3H), 0.71 (d, $J=$ $6.4 \mathrm{~Hz}, 3 \mathrm{H}) ;{ }^{13} \mathrm{C} \mathrm{NMR}\left(75 \mathrm{MHz}, \mathrm{CDCl}_{3}\right) \delta 170.6,166.3,165.6,133.1,132.9,130.6,129.9$, $129.5,129.4,128.4,128.3,121.6,115.1,83.5,81.6,73.4,69.6,69.4,53.7,52.4,46.4,44.4,39.4$, $37.9,36.5,35.6,33.9,33.8,33.2,31.4,28.3,27.2,26.9,25.6,21.4,13.9$, 12.1, 10.7; HRMS (ESI) $\mathrm{C}_{43} \mathrm{H}_{54} \mathrm{O}_{9} \mathrm{Na}[\mathrm{M}+\mathrm{Na}]^{+}$calcd. 737.3666, found 737.3669.

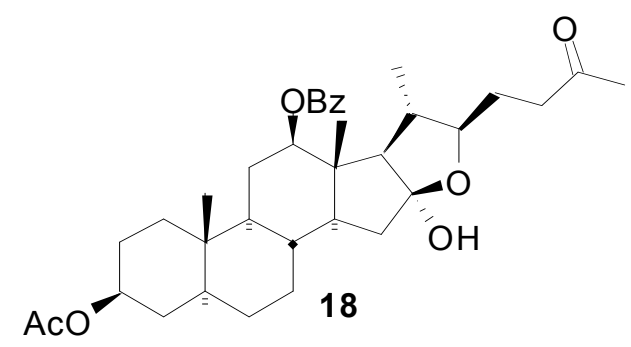

Colorless oil; ${ }^{1} \mathrm{H}$ NMR (300 MHz, $\left.\mathrm{CDCl}_{3}\right) \delta 7.95$ (d, $\left.J=7.0 \mathrm{~Hz}, 2 \mathrm{H}\right), 7.49-7.54$ (m, 1H), 7.38 - $7.43(\mathrm{~m}, 2 \mathrm{H}), 4.87(\mathrm{dd}, J=11.1,4.1 \mathrm{~Hz}, 1 \mathrm{H}), 4.60-4.67(\mathrm{~m}, 1 \mathrm{H}), 3.75(\mathrm{dt}, J=8.8,2.3 \mathrm{~Hz}$, 1H), 2.61 (ddd, $J=17.6,10.8,5.9 \mathrm{~Hz}, 1 \mathrm{H}), 2.44$ (ddd, $J=17.9,9.4,5.9 \mathrm{~Hz}, 1 \mathrm{H}), 2.10$ (s, 3H), $1.96(\mathrm{~s}, 3 \mathrm{H}), 0.95(\mathrm{~s}, 3 \mathrm{H}), 0.81(\mathrm{~s}, 3 \mathrm{H}), 0.74(\mathrm{~d}, J=6.4 \mathrm{~Hz}, 3 \mathrm{H}) ;{ }^{13} \mathrm{C} \mathrm{NMR}\left(75 \mathrm{MHz}, \mathrm{CDCl}_{3}\right)$ $\delta 208.7,170.6,165.6,132.9,130.4,129.3,128.4,114.7,88.0,81.6,73.3,69.9,54.1,52.4,46.0$, $44.4,40.8,39.8,38.4,36.4,35.5,33.9,33.7,31.4,29.8,28.2,27.3,27.2,26.6,21.3,17.9,12.0$, 10.9; HRMS (ESI) $\mathrm{C}_{35} \mathrm{H}_{48} \mathrm{O}_{7} \mathrm{Na}[\mathrm{M}+\mathrm{Na}]^{+}$calcd. 603.3298, found 603.3311. 


\section{${ }^{1}$ H NMR Data for Previously Synthesized Compounds}

(Compounds 3, 6, 10, 12, 16, 20, and 22)

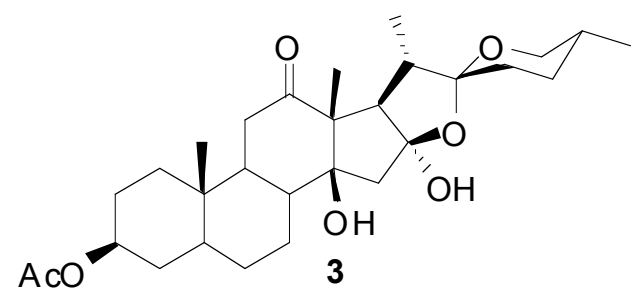

${ }^{1} \mathrm{H}$ NMR (300 MHz, $\left.\mathrm{CDCl}_{3}\right)$ d 4.60-4.65 ( (m, 1H), 3.44-3.60 (m, 3H), $3.21(\mathrm{~d}, J=8.5 \mathrm{~Hz}, 1 \mathrm{H})$, 2.24-2.44 (m, 3H), 2.02-2.21 (m, 2H), 1.94 (s, 3H), 1.17 (s, 3H), 1.00 (d, $J=6.9 \mathrm{~Hz}), 0.87$ (s, $3 \mathrm{H}), 0.80(\mathrm{~d}, J=6.1 \mathrm{~Hz})$

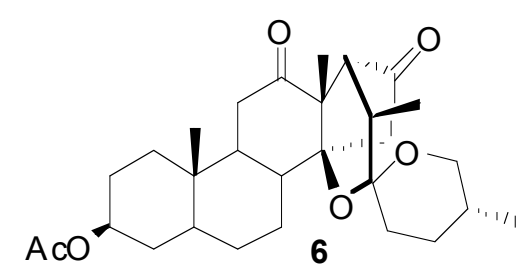

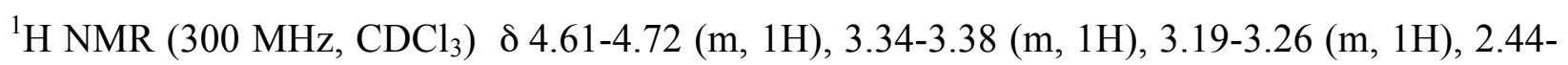
$2.62(\mathrm{~m}, 3 \mathrm{H}), 2.02-2.29(\mathrm{~m}, 4 \mathrm{H}), 2.00(\mathrm{~s}, 3 \mathrm{H}), 1.27$ (s, 3H), 0.99 (d, $J=6.9 \mathrm{~Hz}, 3 \mathrm{H}), 0.95(\mathrm{~s}$, $3 \mathrm{H}), 0.76(\mathrm{~d}, J=5.9,3 \mathrm{H})$

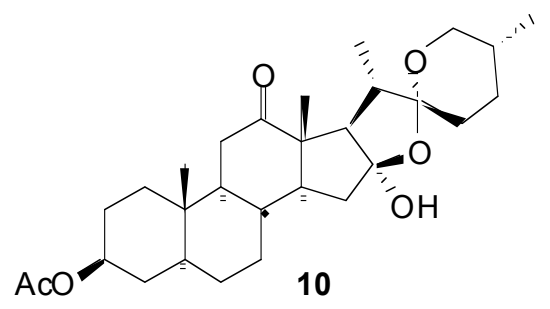

${ }^{1} \mathrm{H}$ NMR (400 MHz, $\left.\mathrm{CDCl}_{3}\right) \delta$ 4.55-4.70 (m, $\left.1 \mathrm{H}\right), 3.40-3.58(\mathrm{~m}, 1 \mathrm{H}), 2.45(\mathrm{~d}, 1 \mathrm{H}, \mathrm{J}=9.1 \mathrm{~Hz})$, 2.32 (t, 1 H), 2.16 (dd, 1H), 1.94 (s, 3 H), 1.05 (d, 1 H, J = 7 Hz), 0.94(s, 3 H) 0.84 (s, 3 H) 0.74 $(\mathrm{d}, \mathrm{J}=6.8 \mathrm{~Hz})$ 


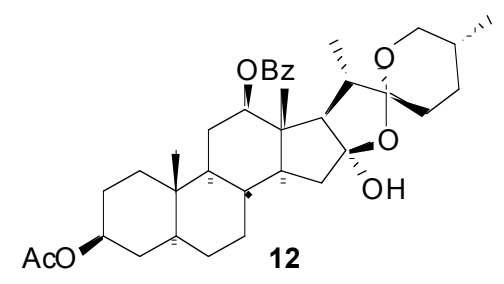

${ }^{1} \mathrm{H}$ NMR (400 MHz, CDCl$)$ ) 7.95 (m, $\left.2 \mathrm{H}\right), 7.50$ (m, 1H), 3.38 (m, 2H), 490 (m, 1H), 4.57-4.80 (m, 1H), 3.55 (br, 1 H), 3.95 (m, 2 H), 1.95 (s, 1H), 0.91 (s, 1H), 0.77 (d, 3 H, J=7 Hz), 7.74 (d, 3 $\mathrm{H}, \mathrm{J}=7 \mathrm{~Hz})$

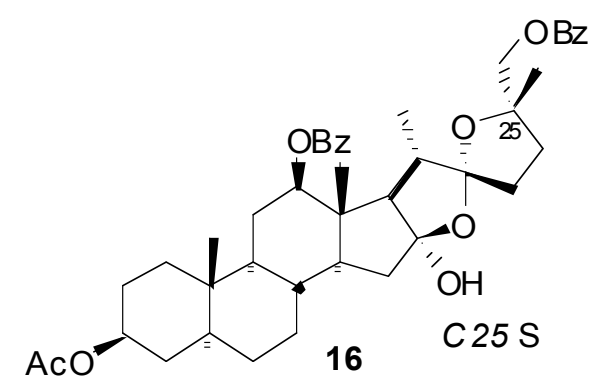

${ }^{1} \mathrm{H}$ NMR $\left(300 \mathrm{MHz}, \mathrm{CDCl}_{3}\right) \delta 7.40-8.13(\mathrm{~m}, 10 \mathrm{H}), 4.94(\mathrm{dd}, J=11.0,4.6 \mathrm{~Hz}, 1 \mathrm{H}), 4.64(1 \mathrm{H}$, m), 4.37 (dd, $J=16.1,11.0 \mathrm{~Hz}, 1 \mathrm{H}), 1.99$ (s, 3H), 1.17 (s, 3H), 0.98 (s, 3H), 0.84 (s, 3H), 0.76 (d, $J=6.8 \mathrm{~Hz}, 3 \mathrm{H})$.

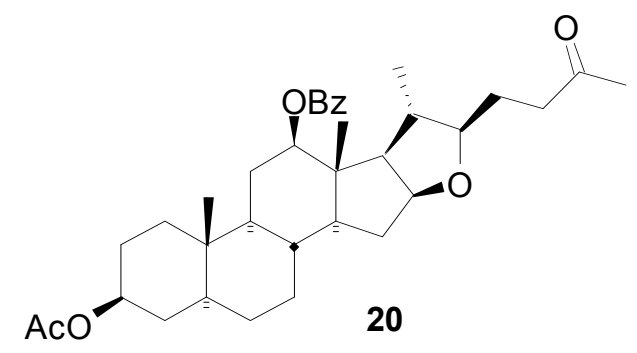

${ }^{1} \mathrm{H}$ NMR $\left(300 \mathrm{MHz}, \mathrm{CDCl}_{3}\right) \delta 7.99(\mathrm{~d}, J=7.0 \mathrm{~Hz}, 2 \mathrm{H}), 7.52-7.57(\mathrm{~m}, 1 \mathrm{H}), 7.41-7.46(\mathrm{~m}$, 2H), 4.78 (dd, $J=11.1,4.1 \mathrm{~Hz}, 1 \mathrm{H}), 4.62-4.69$ (m, 1H), 4.28 (dd, $J=14.8,7.0 \mathrm{~Hz}, 1 \mathrm{H}), 3.23$ (dt, $J=14.6,7.0 \mathrm{~Hz}, 1 \mathrm{H}), 2.66(\mathrm{ddd}, J=18.2,10.0,5.3 \mathrm{~Hz}, 1 \mathrm{H}), 2.46(\mathrm{ddd}, J=17.9,10.0,5.9$ Hz, 1H), 2.11 (s, 3H), 1.99 (s, 3H), 0.99 (s, 3H), 0.83 (s, 3H), 0.71 (d, $J=5.9 \mathrm{~Hz}, 3 \mathrm{H})$ 


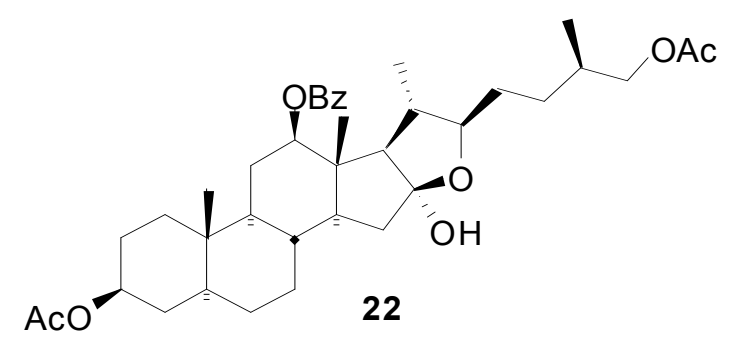

${ }^{1} \mathrm{H}$ NMR $\left(300 \mathrm{MHz}, \mathrm{CDCl}_{3}\right) \delta 7.99(\mathrm{~d}, J=7.6 \mathrm{~Hz}, 2 \mathrm{H}), 7.52-7.56(\mathrm{~m}, 1 \mathrm{H}), 7.40-7.45(\mathrm{~m}$, 2H), $4.91(\mathrm{dd}, J=11.1,4.1 \mathrm{~Hz}, 1 \mathrm{H}), 4.63-4.70(\mathrm{~m}, 1 \mathrm{H}), 3.95(\mathrm{dd}, J=10.5,5.9 \mathrm{~Hz}, 1 \mathrm{H}), 3.82$ (dd, $J=10.5,7.0 \mathrm{~Hz}, 1 \mathrm{H}), 3.74-3.79(\mathrm{~m}, 1 \mathrm{H}), 2.24$ (br s, 1H), 2.02 (s, 3H), 1.99 (s, 3H), 0.98 (s, 3H), 0.91 (d, $J=6.4 \mathrm{~Hz}, 3 \mathrm{H}), 0.83$ (s, 3H), 0.76 (d, $J=6.4 \mathrm{~Hz}, 3 \mathrm{H})$ 


\section{${ }^{1} \mathrm{H}$ and ${ }^{13} \mathrm{C}$ NMR Spectra of Newly Synthesized Compounds}

(Compounds 9, 14, 17, 18)

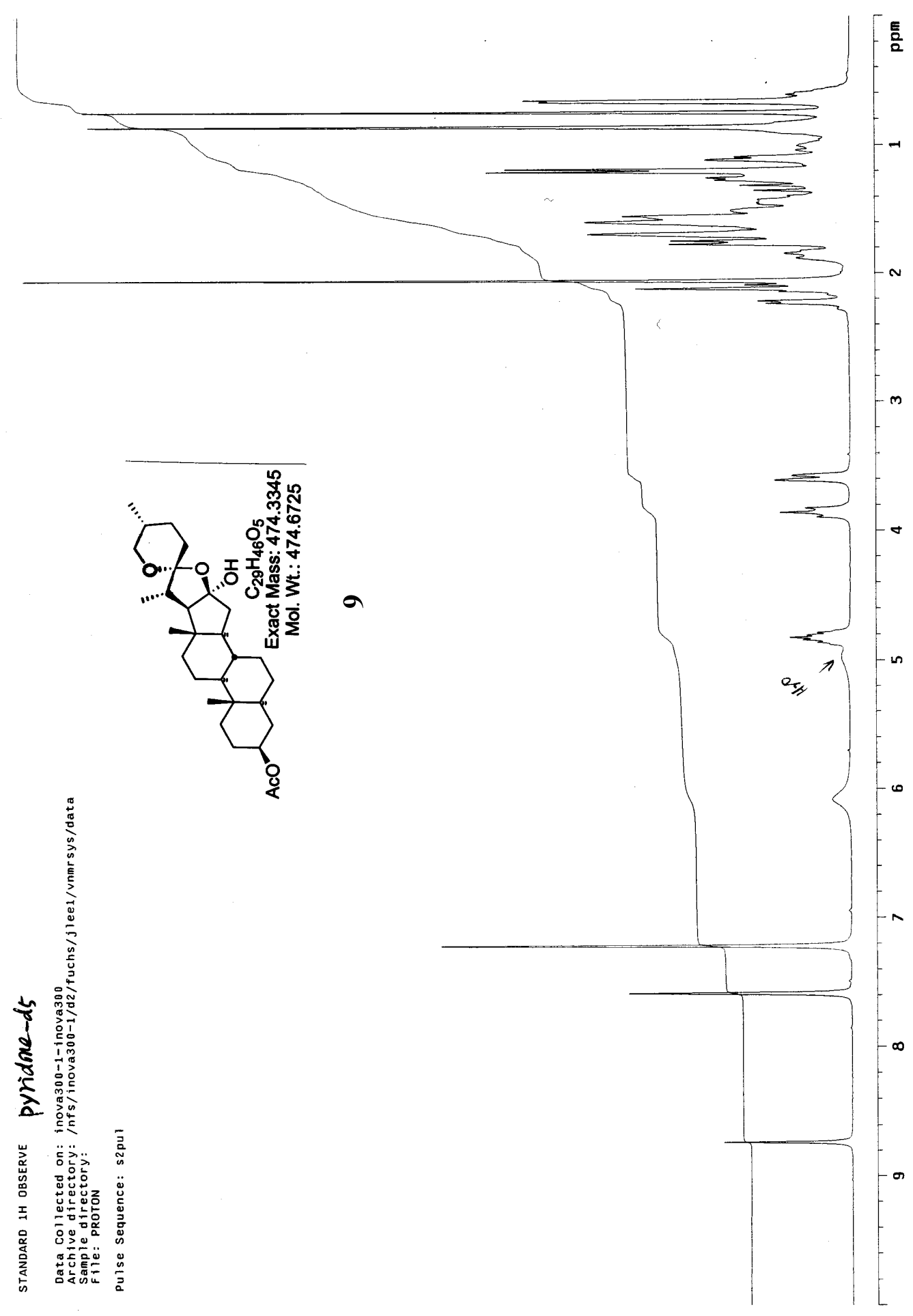




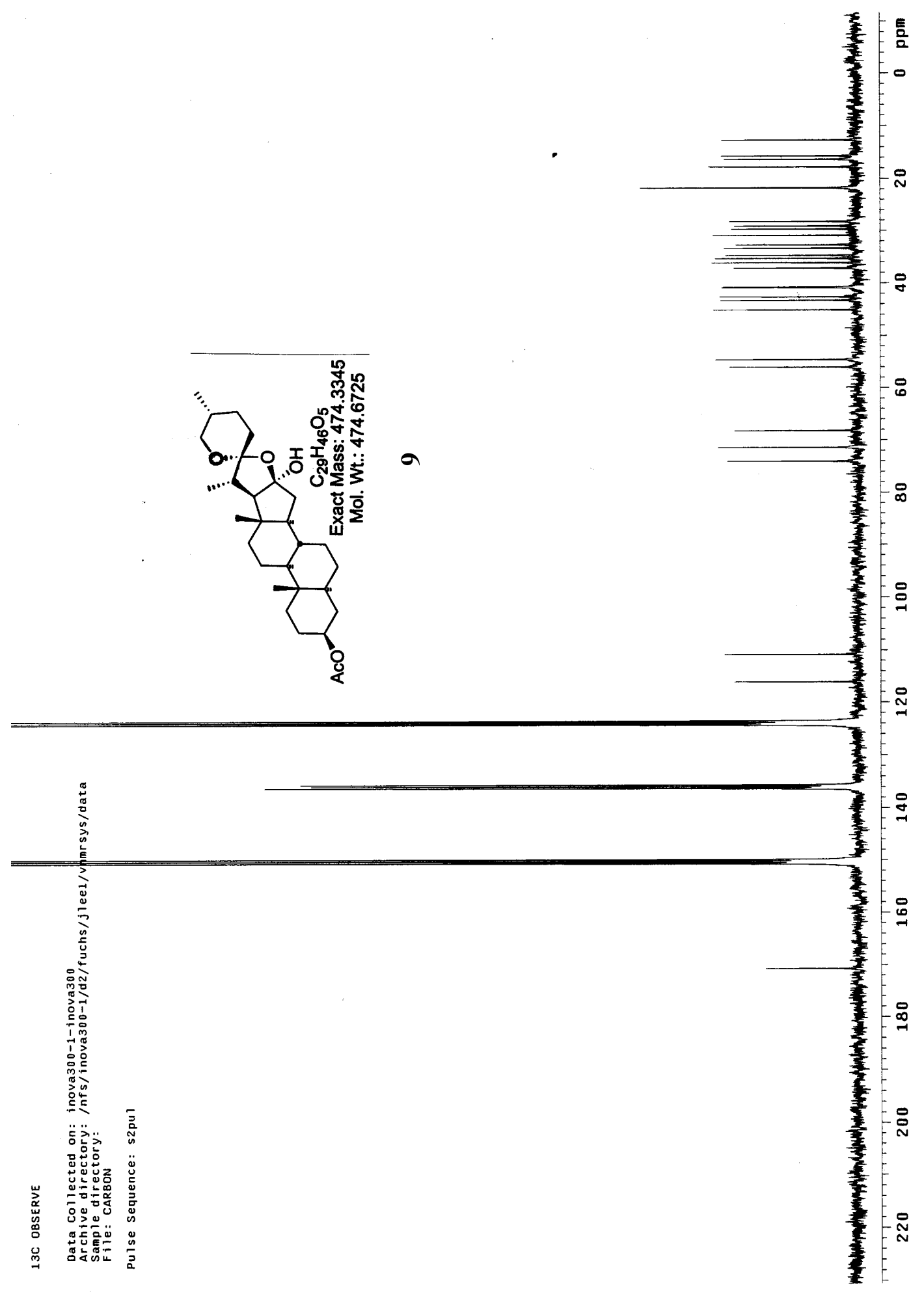




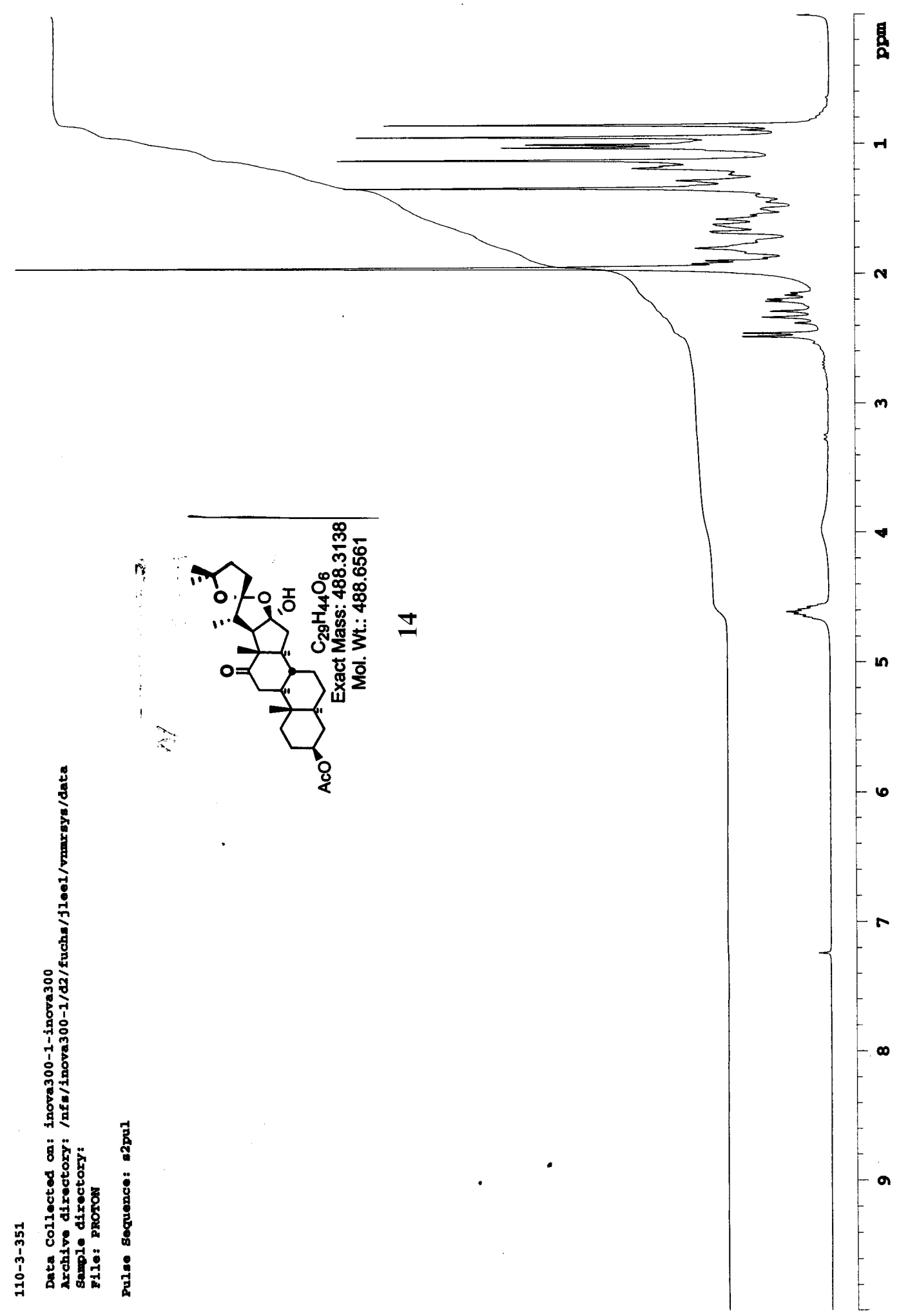



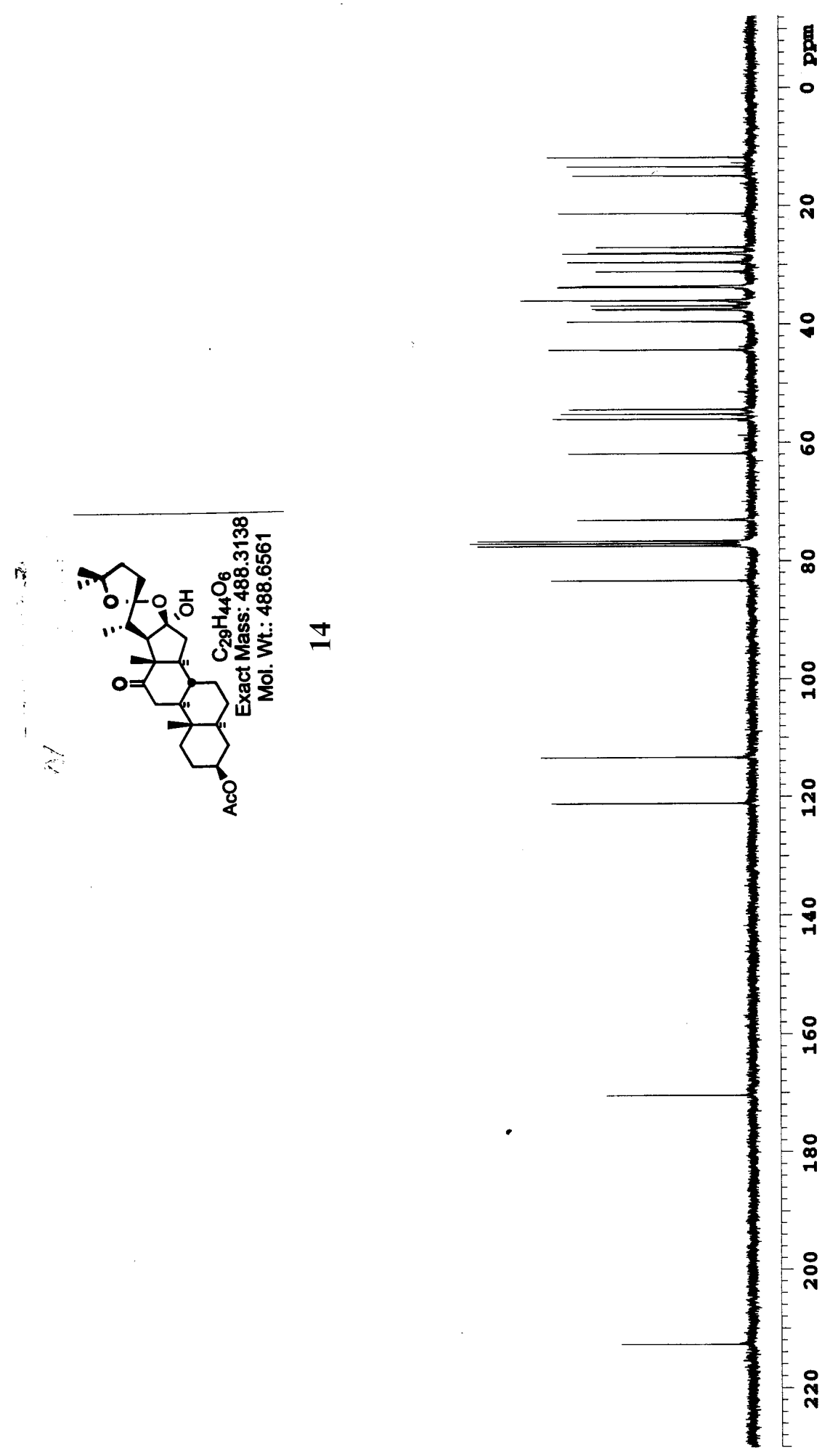


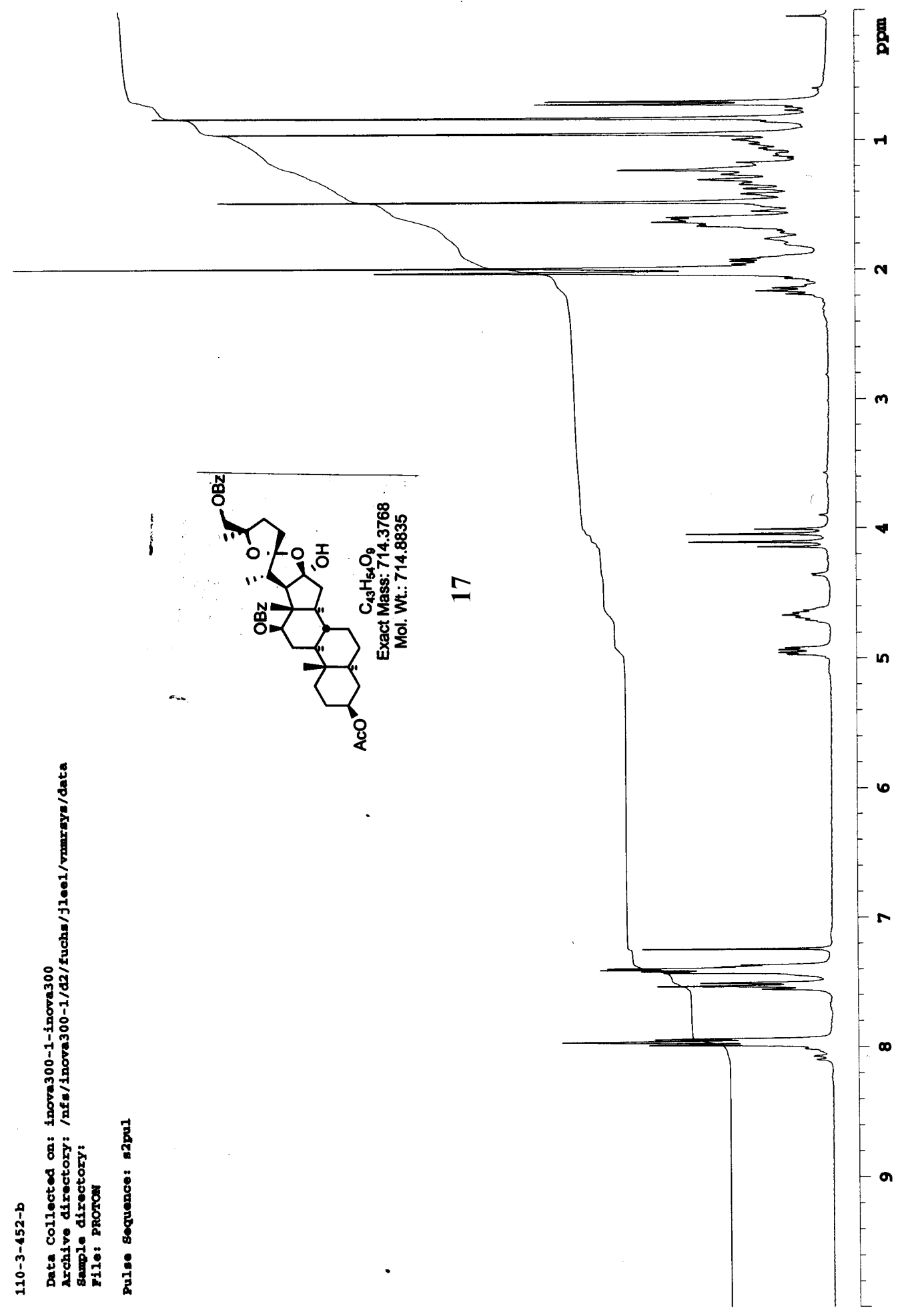




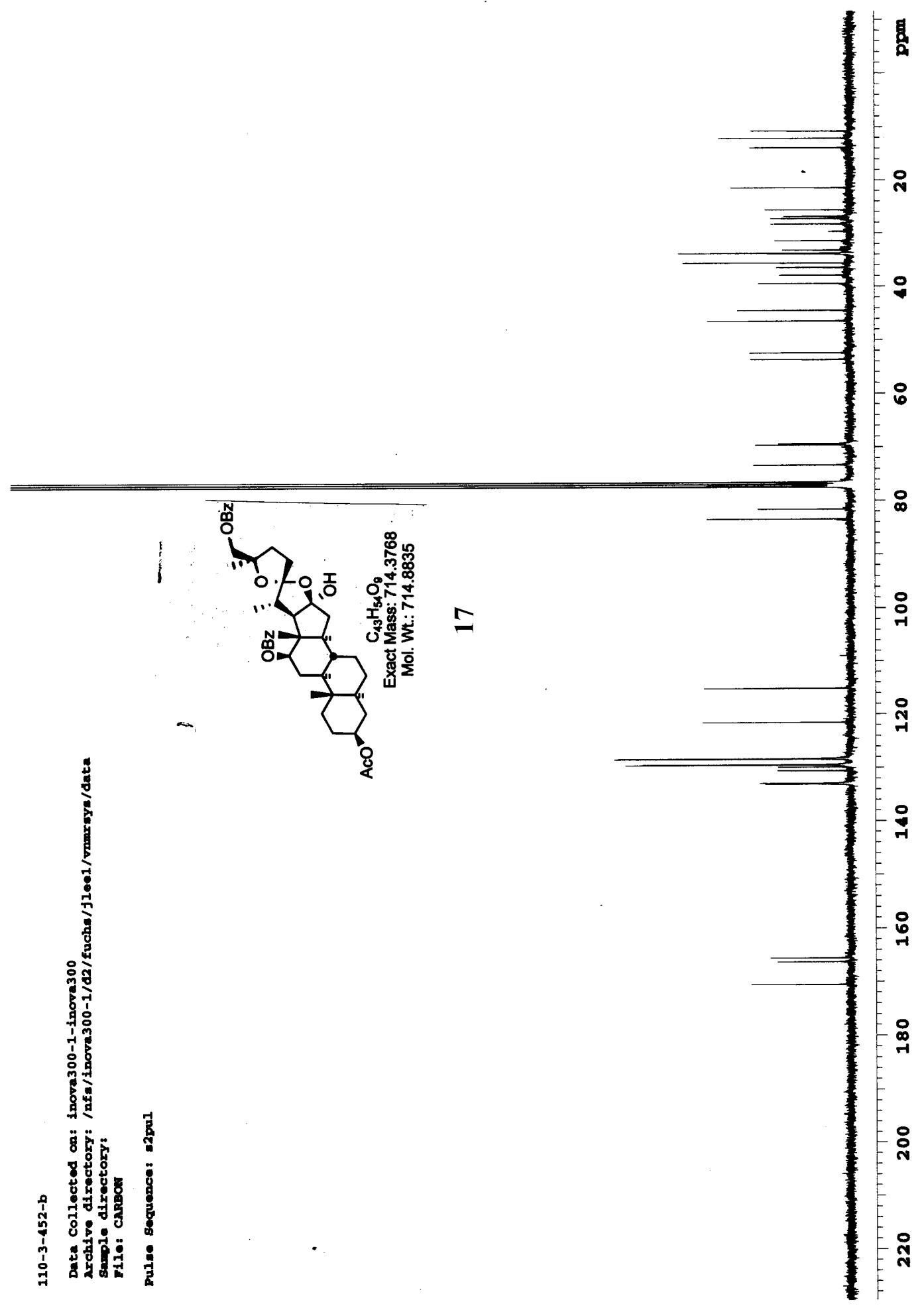




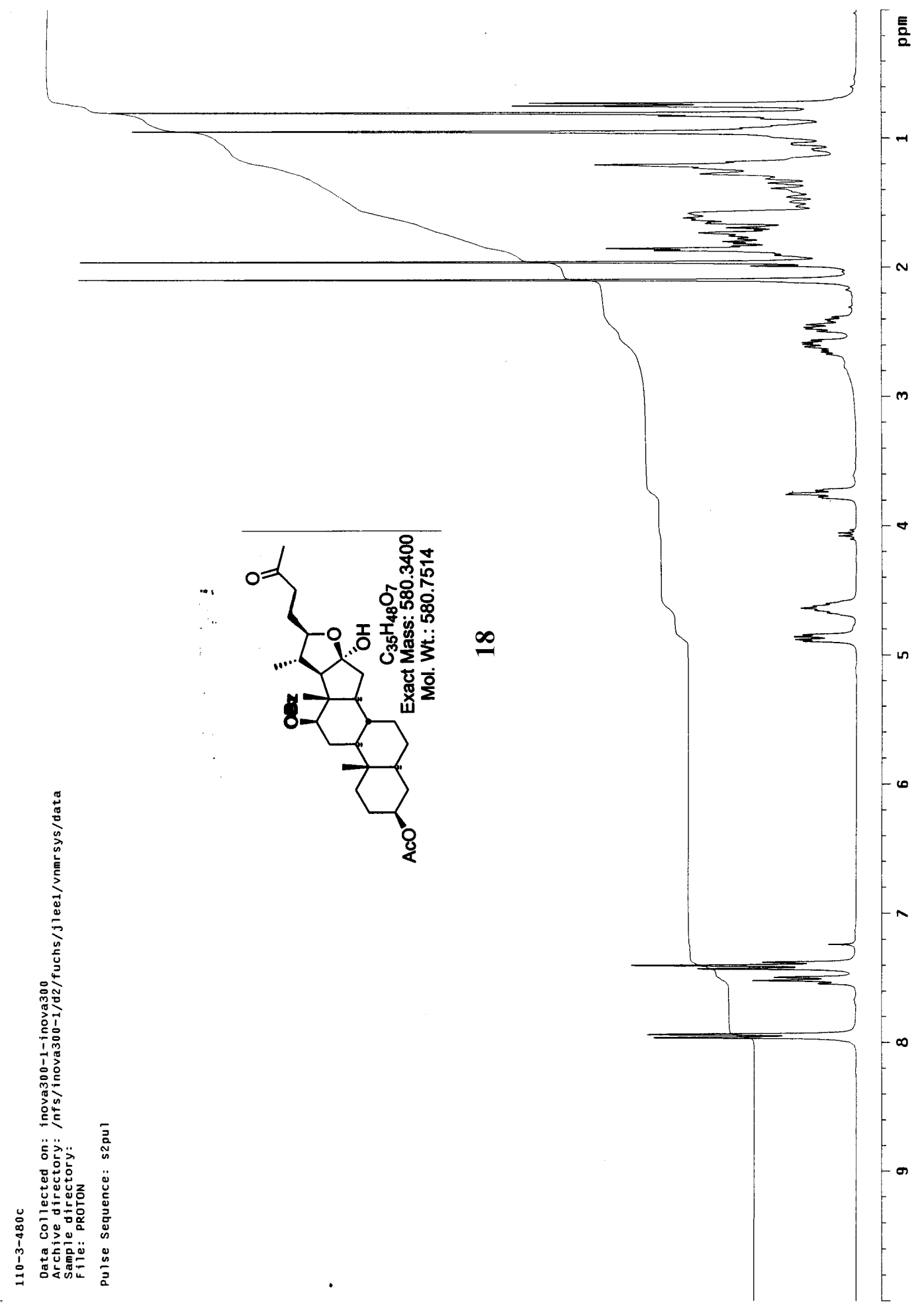



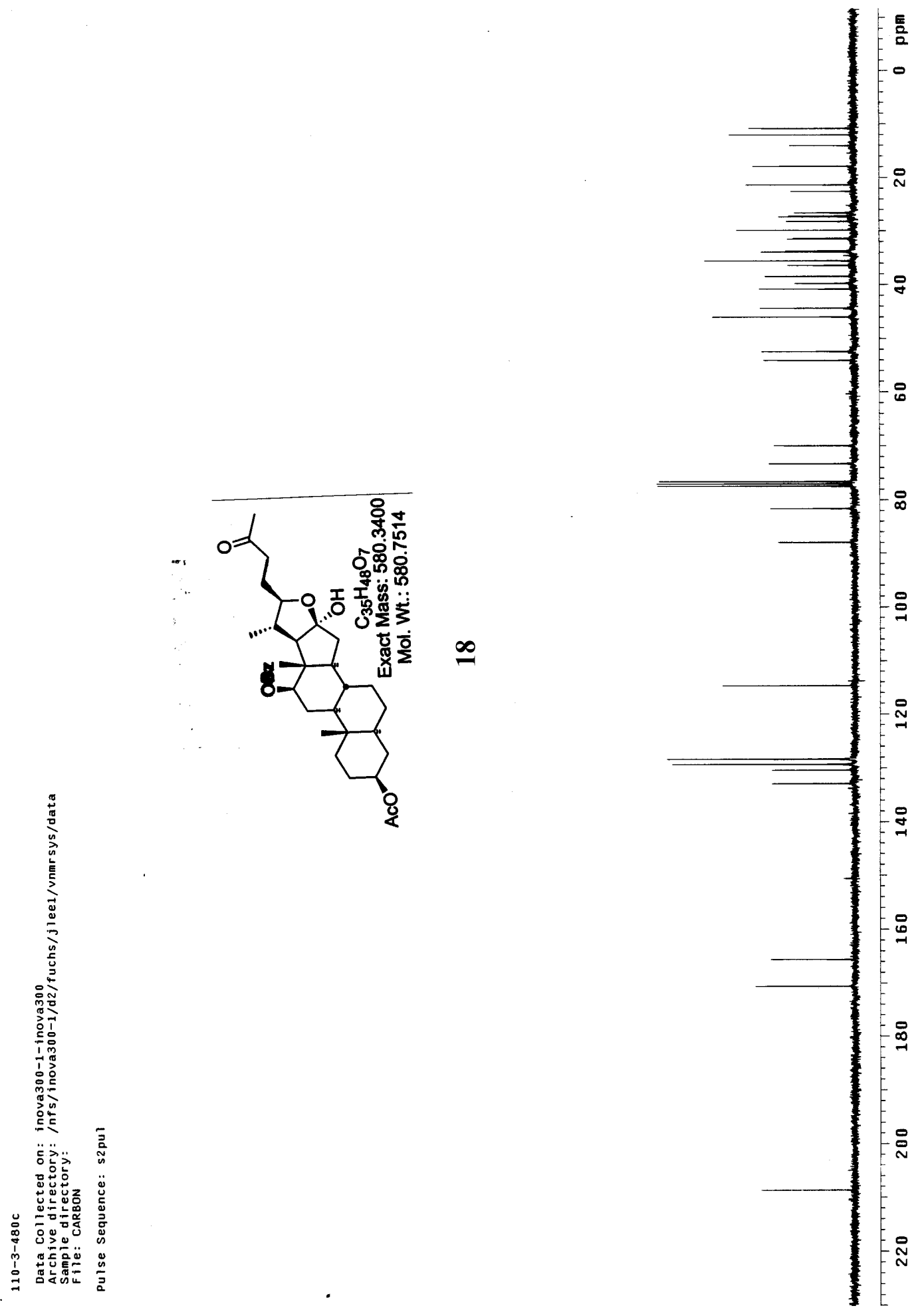


\section{${ }^{1}$ H NMR Spectra of Previously Synthesized Compounds}

(Compounds 3, 6, 10, 12, 16, 20, and 22)

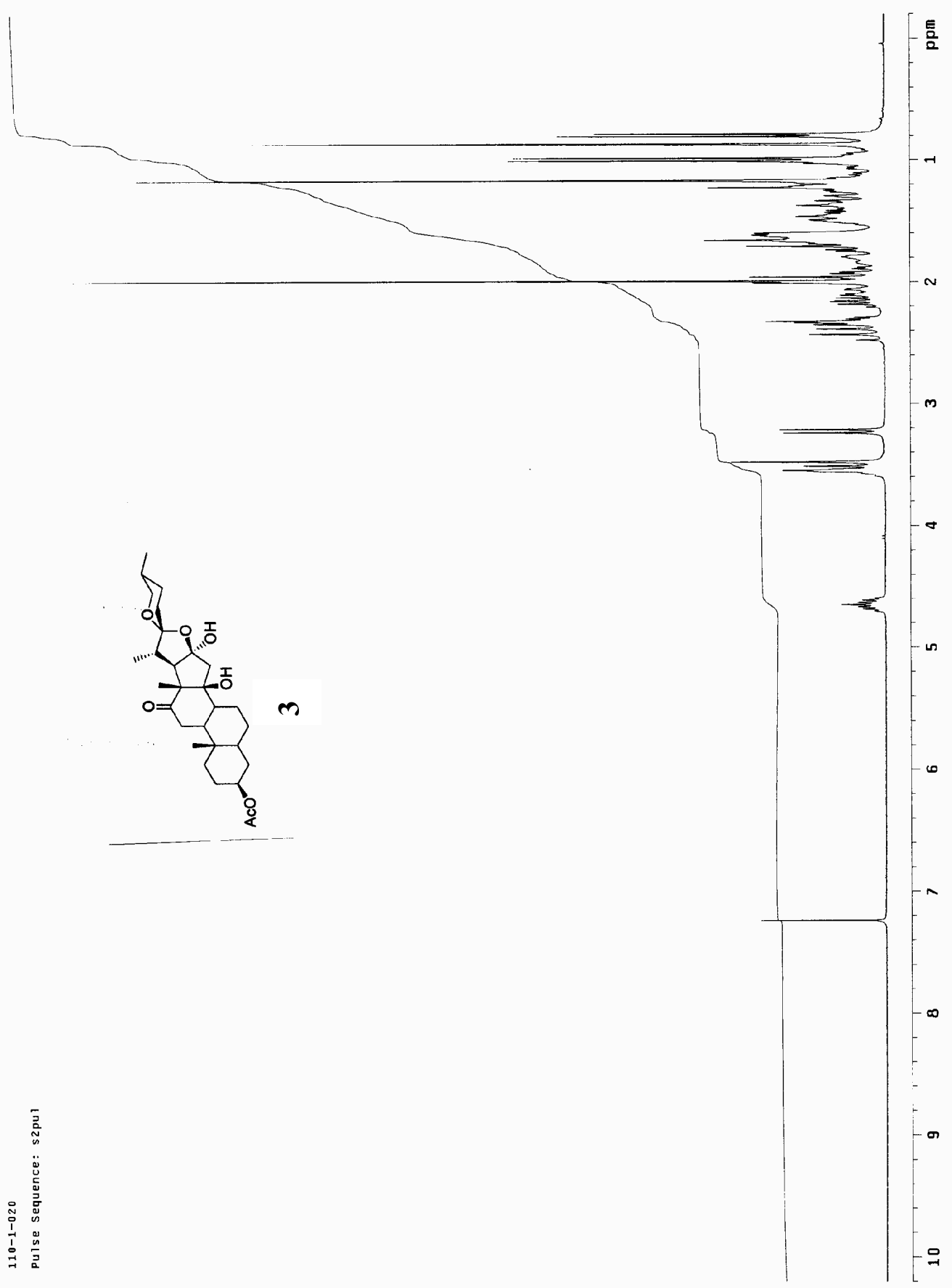




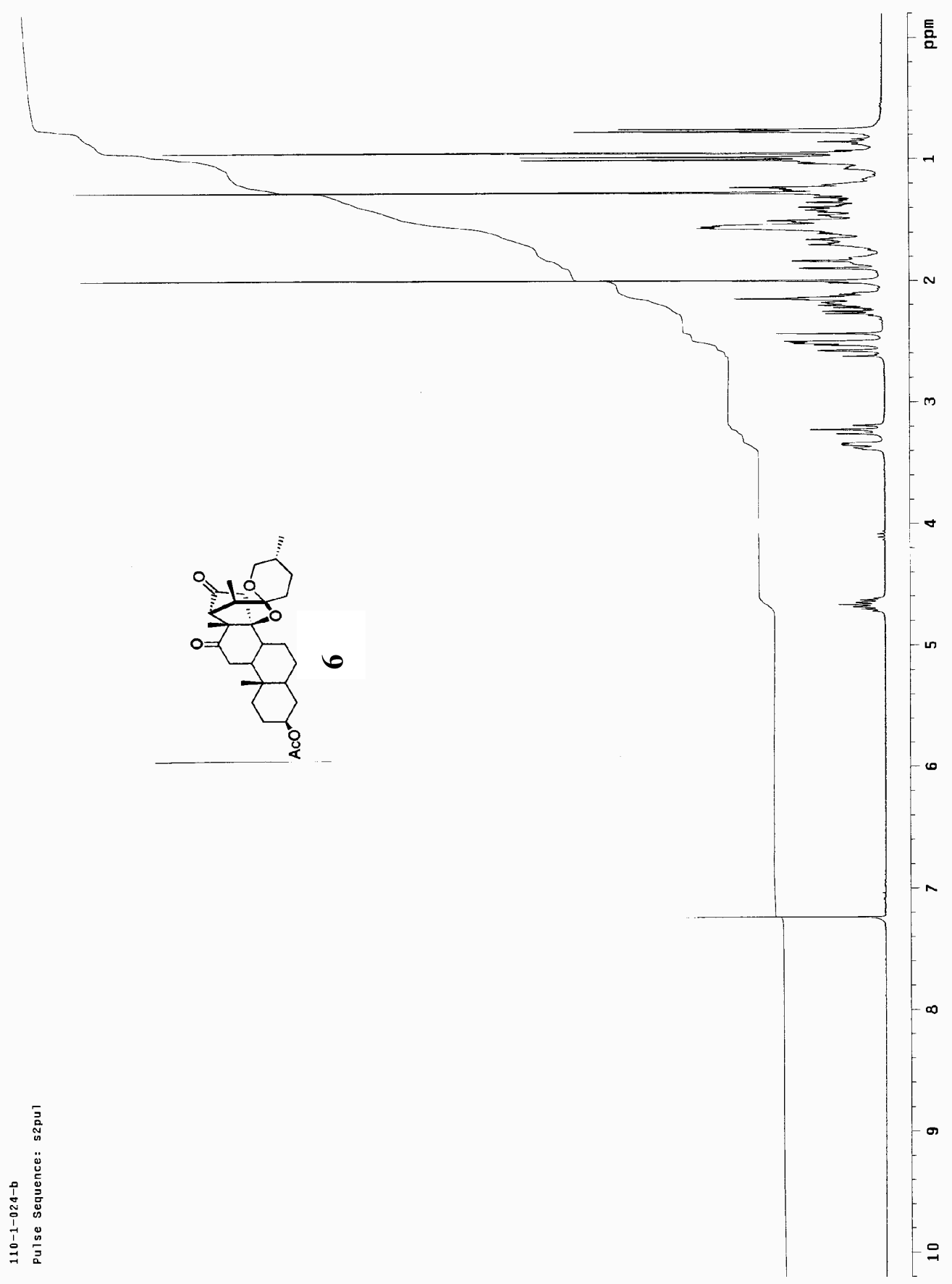




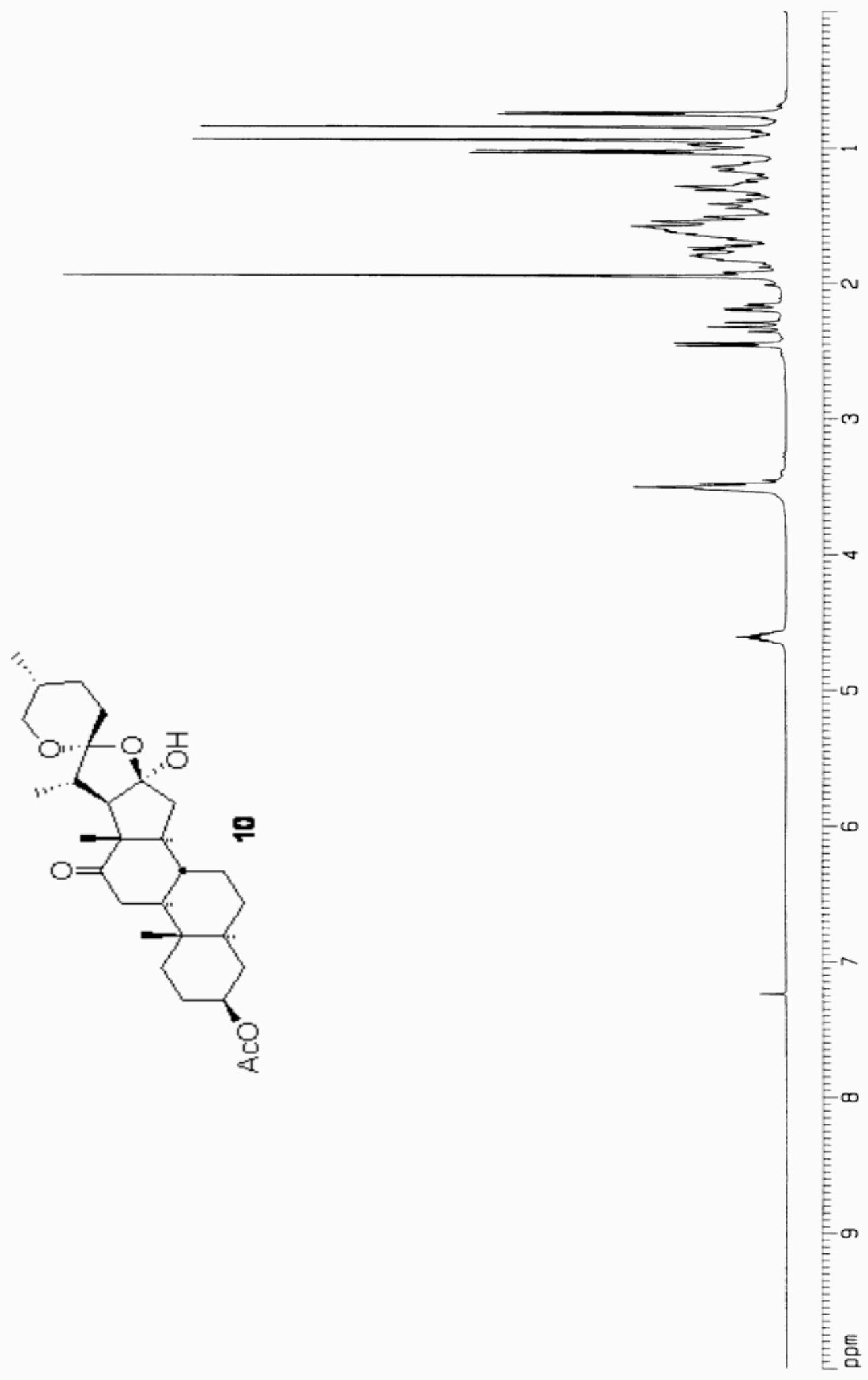




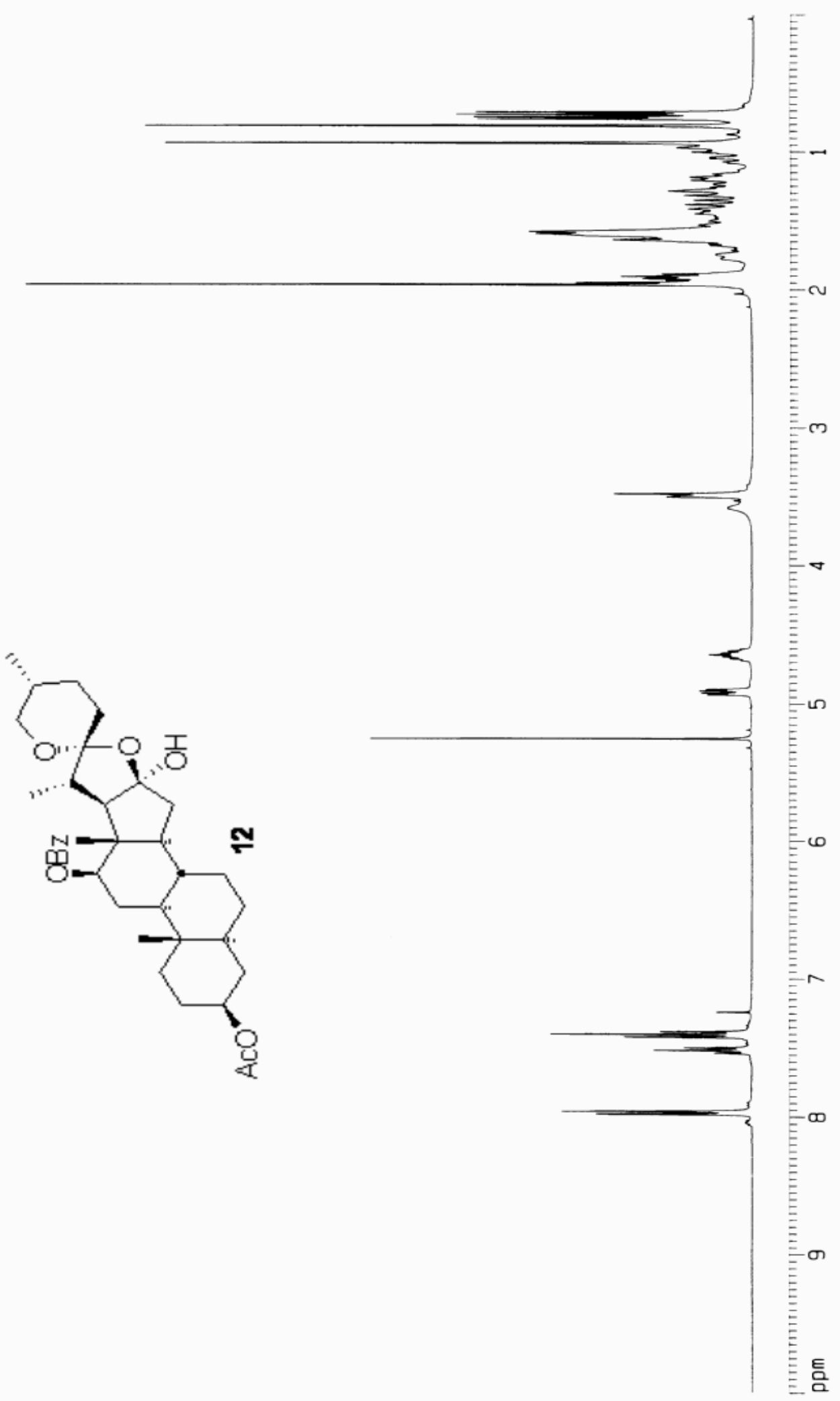


S1

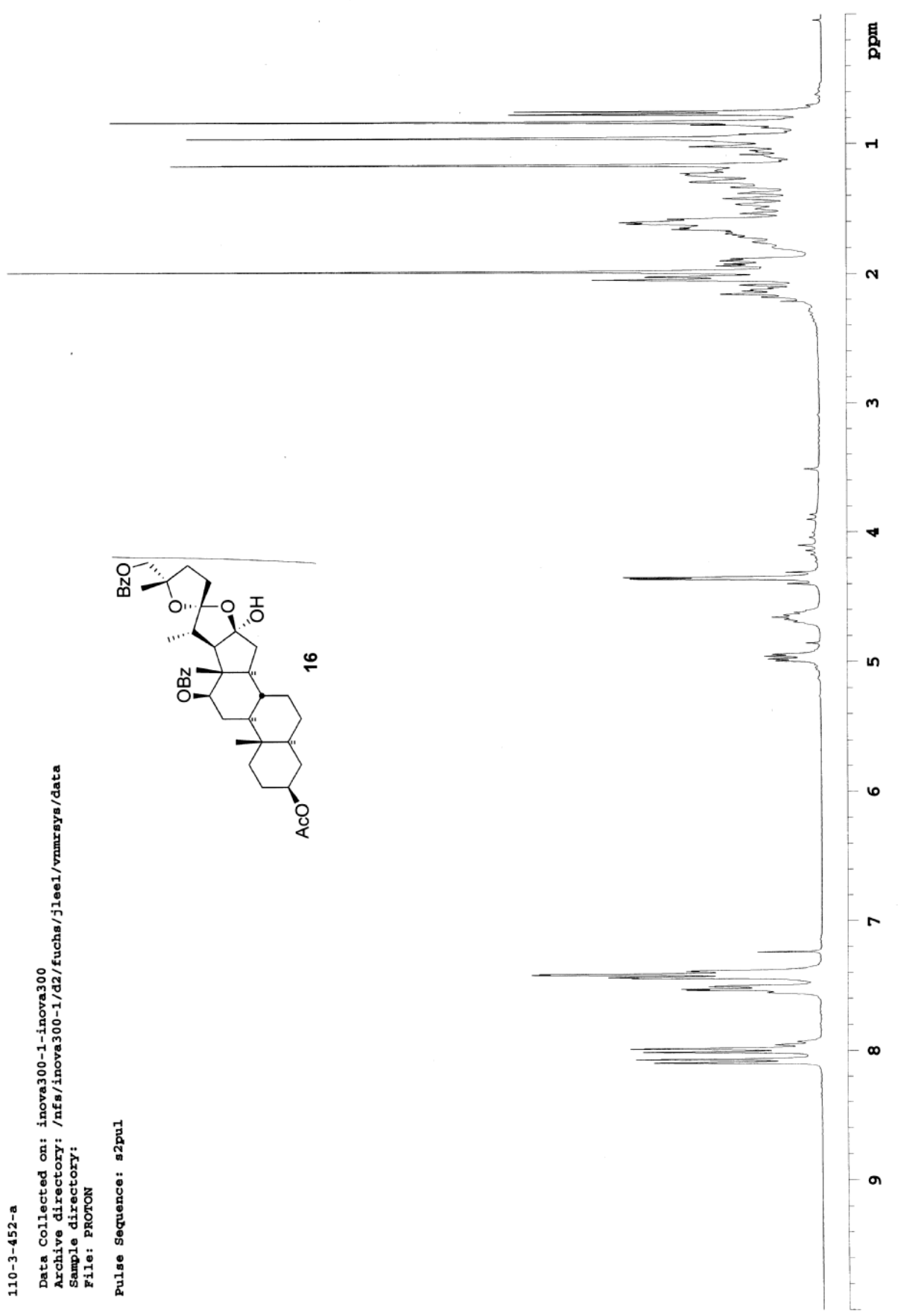

S22 


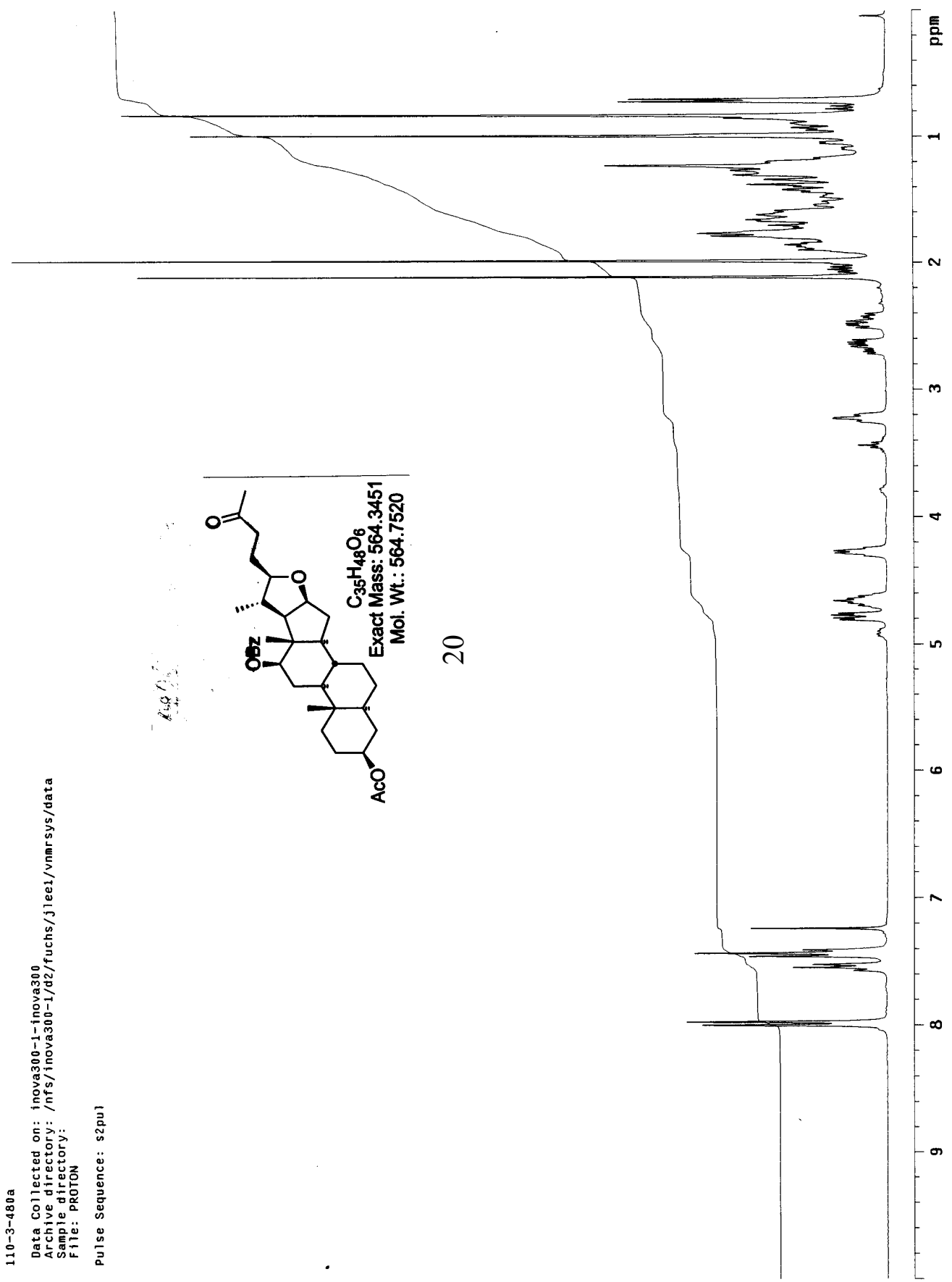




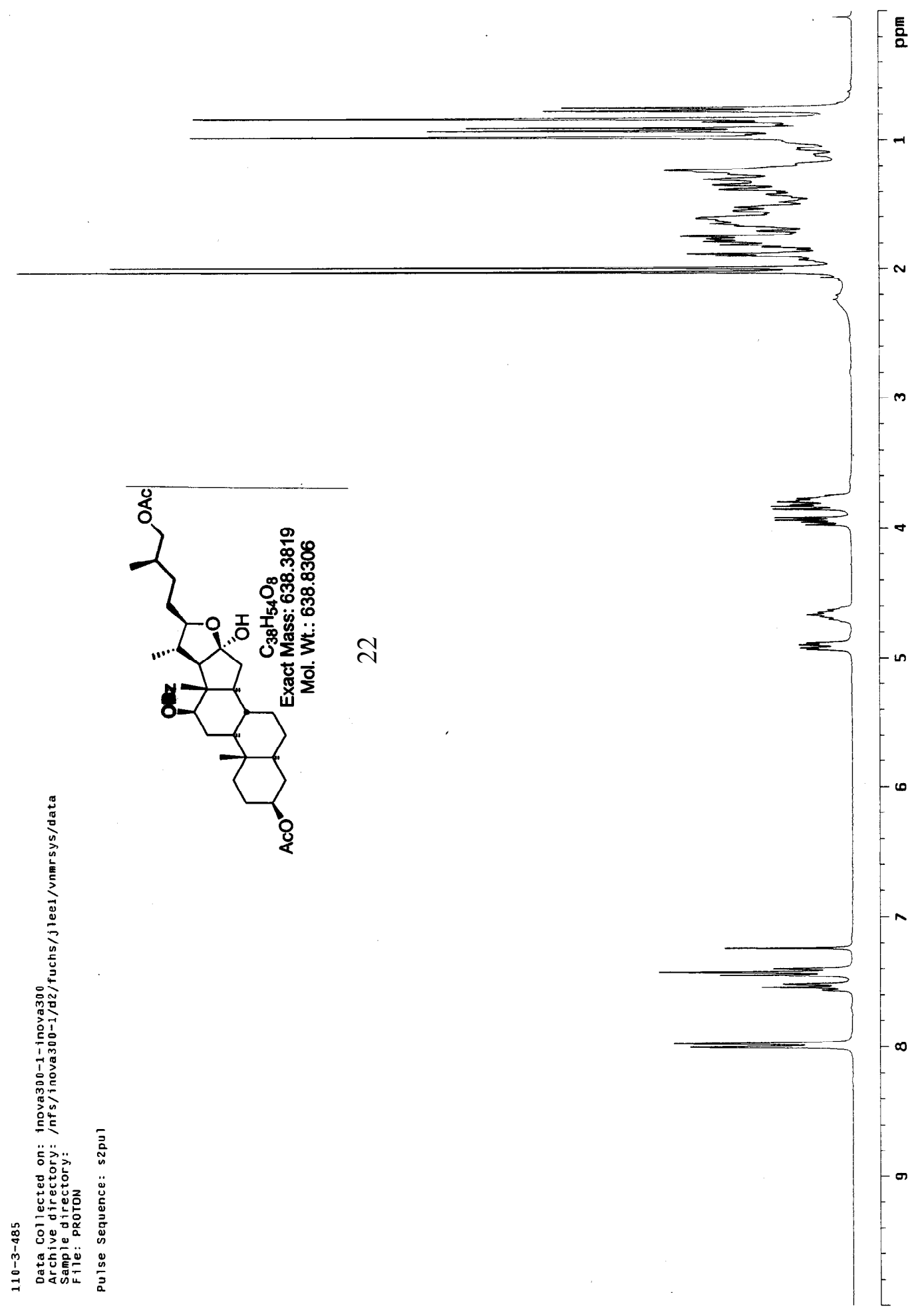

